\title{
Combined method for treating gastrocutaneous fistula after percutaneous endoscopic gastrostomy removal
}

\author{
Juliana Silveira Lima de CASTRO, Joao Guilherme Guerra de Andrade Lima CABRAL,
} Adriane Graicer PELOSOF, Alvaro Moura SERAPHIM and Claudia Sztokfisz ZITRON

A 56-year-old woman with food leaking by gastrocutaneous fistula (GCF), after removal of a $20 \mathrm{Fr}$ percutaneous endoscopic gastrostomy (PEG), unresponsive to clinical treatment. She had PEG for 6 months, due to dysphagia and weight loss, related to squamous cell carcinoma of the esophagus and treatment with chemotherapy and radiotherapy.

We chose to close the ostomy with a simple hybrid technique, electrocoagulation associated with percutaneous suture guided by endoscopy. (E-VIDEO*). The procedure was performed with the patient under deep sedation and local anesthesia. Upper digestive endoscopy was performed identifying the gastric orifice of the GCF. (FIGURE 1). Initially electrocoagulation of the orifice, using coagulation current 40 Watts followed by percutaneous punctures on each corner of the GCF with a $14 \mathrm{G}$ peripheral intravenous catheter. (FIGURE 2). Subsequently a 3-0 nylon monofilament suture folded in half is passed through the catheter, forming the "loop" aspect. (FIGURE 3). The next step is to introduce a second 3-0 monofilament suture on the opposite corner catheter. This last

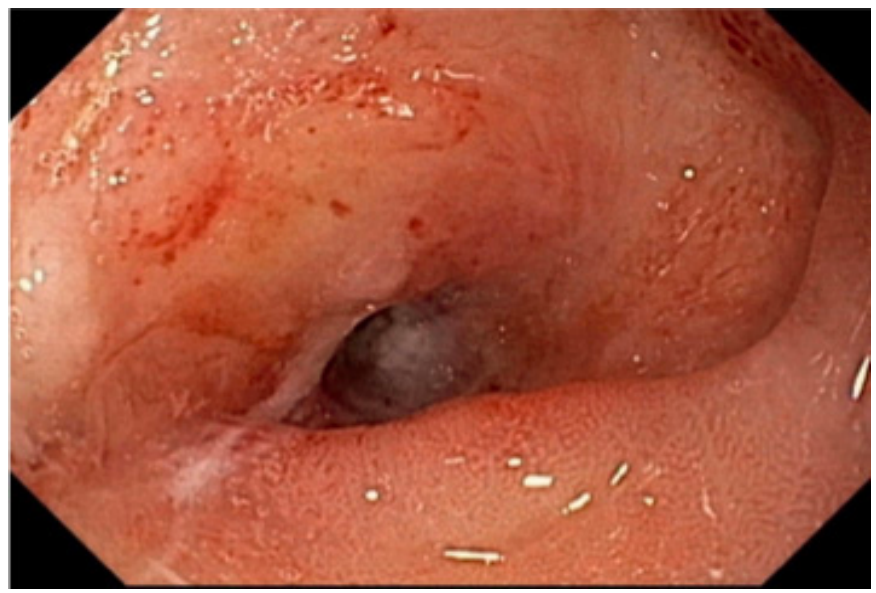

FIGURE 1. Upper digestive endoscopy was performed identifying the gastric orifice of the gastrocutaneous fistula.

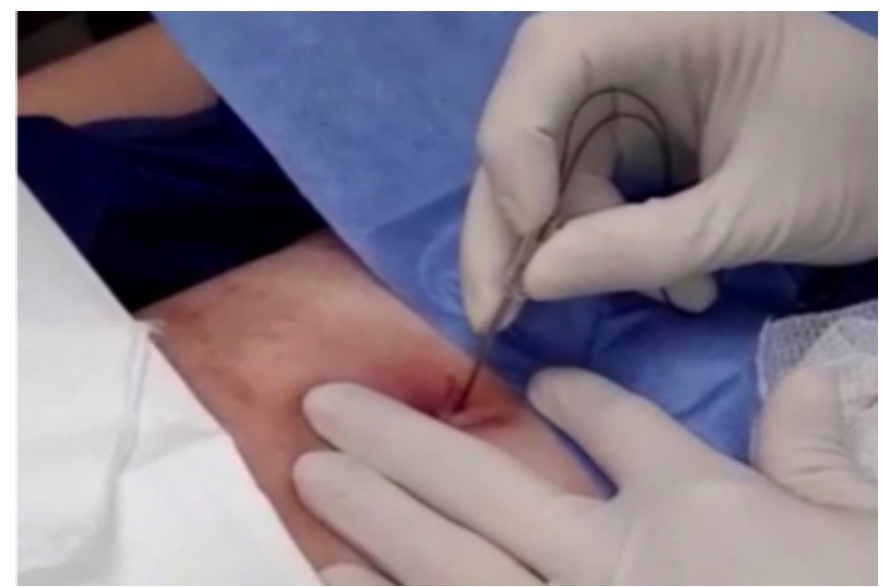

FIGURE 2. Percutaneous punctures on each corner of the gastrocutaneous fistula with a $14 \mathrm{G}$ peripheral intravenous catheter.

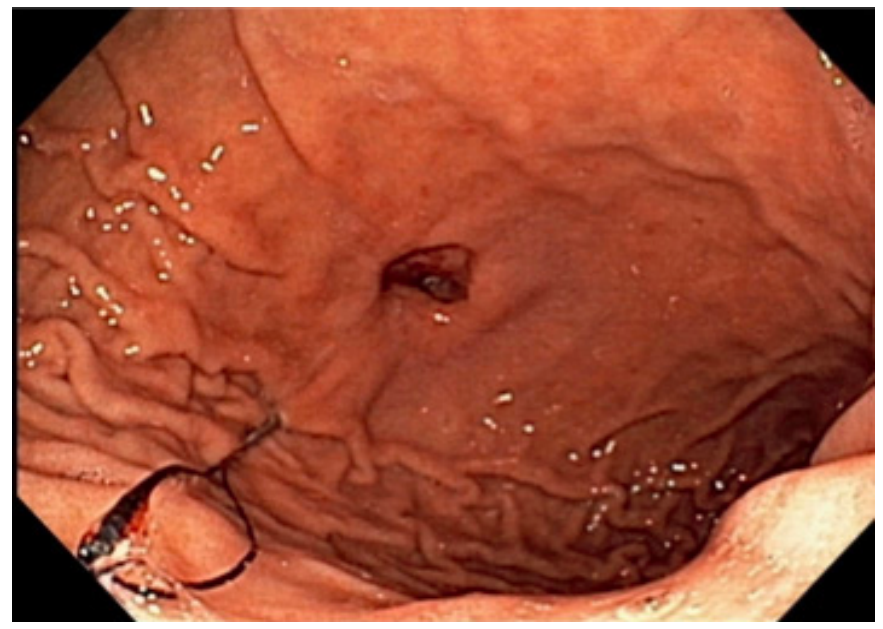

FIGURE 3. "Loop" aspect.

Declared conflict of interest of all authors: none

Disclosure of funding: no funding received

A.C. Camargo Cancer Center, Unidade de Endoscopia, São Paulo, SP, Brasil.

Corresponding author: Juliana de Castro. E-mail: julianasilveira_@hotmail.com

*E-VIDEO: https://youtu.be/m5tyMpP8FgU 
suture should be guided by a biopsy forceps through the priorly formed suture "loop" under direct endoscopy view. (FIGURE 4). Once the first suture loop is pulled, the second suture will form a second loop on the gastric side with its booth extremities on the skin side, allowing the GCF to be closed by tying a surgical knot. (FIGURE 5).

In the follow up, patient returns after 15 days to remove the surgical knot with resolution of the GCF, without leakage of diet by GCF.

The opening of the wall after removal of PEG usually closes in about 1 to 3 days $^{(1)}$. Persistent GCF after PEG removal is rare and uncommon in adults ${ }^{(2)}$. Surgical treatment has been largely re-

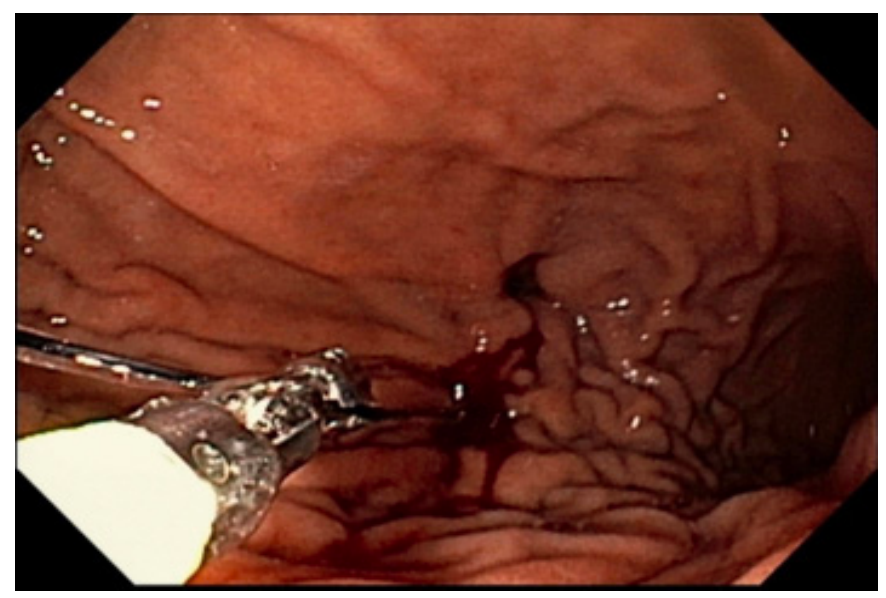

FIGURE 4. Last suture should be guided by a biopsy forceps through the priorly formed suture "loop" under direct endoscopy view. placed by endoscopy and several techniques have been described ${ }^{(3)}$. Electrocoagulation deepithelialize the tract and promote healing ${ }^{(4)}$ and the suture causes mechanical closure ${ }^{(5)}$. The combined method for closing PEG with electrocoagulation associated with suture is simple, safe and has good results.

\section{Orcid}

Juliana Silveira Lima de Castro: 0000-0003-0280-8356.

Joao Guilherme Guerra de A. Lima Cabral: 0000-0001-7607-6982.

Adriane Graicer Pelosof: 0000-0001-9813-5832.

Alvaro Moura Seraphim: 0000-0002-3300-0467.

Claudia Sztokfisz Zitron: 0000-0001-9364-8460.

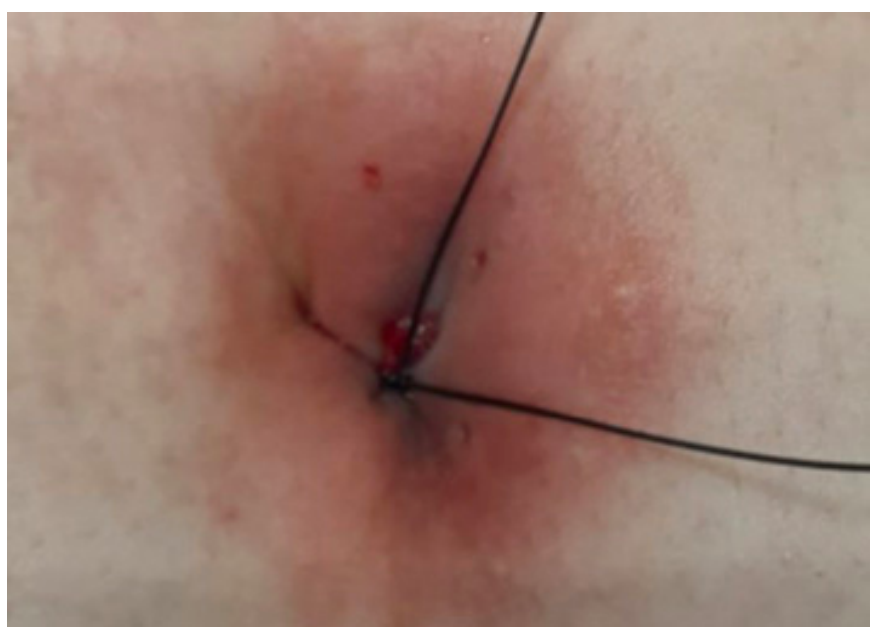

FIGURE 5. Surgical knot.

Castro JSL, Cabral JGGAL, Pelosof AG, Seraphim AM, Zitron CS. Método combinado para tratamento de fístula gastrocutânea após remoção de gastrostomia endoscópica. Arq Gastroenterol. 2021;58(4):571-2.

\section{REFERENCES}

1. Hucl T, Spicak J. Complications of percutaneous endoscopic gastrostomy. Best Pract Res Clin Gastroenterol. 2016;30:769-81.

2. Omer J. Deen, Keely R. Parisian, Campbell Harris, Donald F Kirby. A Novel Procedure for Gastrocutaneous Fistula Closure. J Clin Gastroenterol. 2013;47:608-11.

3. Hameed H, Kalim S, Khan YI. Closure of a nonhealing gastrocutanous fistula using argon plasma coagulation and endoscopic hemoclips. Can J Gastroenterol Hepatol. 2009;23:217e9.
4. Duddempudi S, Ghevariya V, Singh M, Krishnaiah M, Anand S. Treatment of persistently leaking post PEG tube gastrocutaneous fistula in elderly patients with combined electrochemical cautery and endoscopic clip placement. South Med J. 2009;102:585-8.

5. Alberti-Flor JJ. Percutaneous-endoscopic suturing of gastrocutaneous fistula: report of two cases. Gastrointest Endosc. 2002;56:751-53. 